\title{
DETECTION AND ConTROL OF DEPOSITION ON
} PEndant Tubes OF Kraft Chemical Recovery Bollers

Quarterly Report for the Period July - September 1999

\author{
George Kychakoff
}

Combustion Specialists, InC.

Date Published - October 1999

Prepared for the United States

DEPARTMENT OF ENERGY

Under Cooperative Agreement

DE-FC36-99G010375 


\section{DISCLAIMER}

This report was prepared as an account of work sponsored by an agency of the United States Government. Neither the United States Government nor any agency thereof, nor any of their employees, make any warranty, express or implied, or assumes any legal liability or responsibility for the accuracy, completeness, or usefulness of any information, apparatus, product, or process disclosed, or represents that its use would not infringe privately owned rights. Reference herein to any specific commercial product, process, or service by trade name, trademark, manufacturer, or otherwise does not necessarily constitute or imply its endorsement, recommendation, or favoring by the United States Government or any agency thereof. The views and opinions of authors expressed herein do not necessarily state or reflect those of the United States Government or any agency thereof. 


\section{DISCLAIMER}

Portions of this document may be illegible in electronic image products. Images are produced from the best available original document. 


\section{Detection and Control. of Deposition On Pendant Tubes of \\ KRAFT CHEMICAL RECOVERY BOILERS \\ Report for the Period July through September, 1999}

\section{Summary of Project Status and Activities Performed During the Period}

Activities during this period continued to focus on obtaining a clear image of deposits inside an operating recovery boiler (comprising parts of Tasks 1 through 4 of the project work statement).

\section{Calculation of Molecular Interferences}

The theoretical optical absorption for a number of typical recovery boiler conditions were calculated as a function of wavelength using the the HITRAN molecular database. Figure 1 (on the next page) illustrates typical results for the gas composition described in Table 1, at a temperature of $1,056 \mathrm{~K}$ :

Table 1
\begin{tabular}{|c|c|}
\hline Molecule & Mole Fraction \\
\hline CO & $9.19 \mathrm{E}-10$ \\
\hline $\mathrm{CO} 2$ & $1.29 \mathrm{E}-01$ \\
\hline $\mathrm{H} 2 \mathrm{O}$ & $2.42 \mathrm{E}-01$ \\
\hline $\mathrm{H} 2 \mathrm{~S}$ & $1.20 \mathrm{E}-29$ \\
\hline $\mathrm{N} 2$ & $6.14 \mathrm{E}-01$ \\
\hline $\mathrm{O} 2$ & $1.43 \mathrm{E}-02$ \\
\hline $\mathrm{SO} 2$ & $1.80 \mathrm{E}-11$ \\
\hline
\end{tabular}

These calculations suggested that the best optical window to avoid molecular interferences is 3.5 to 4.1 microns. However, there is also a reasonable window in the 8 to 9 micron range. Since the calculations do not take into account the impact of the fume particle scattering, and this scattering which fall off as the fourth power of the wavelength to particle size ratio, the longer wavelength window may actually prove to be the more attractive. The project team decided to investigate both of these windows. 


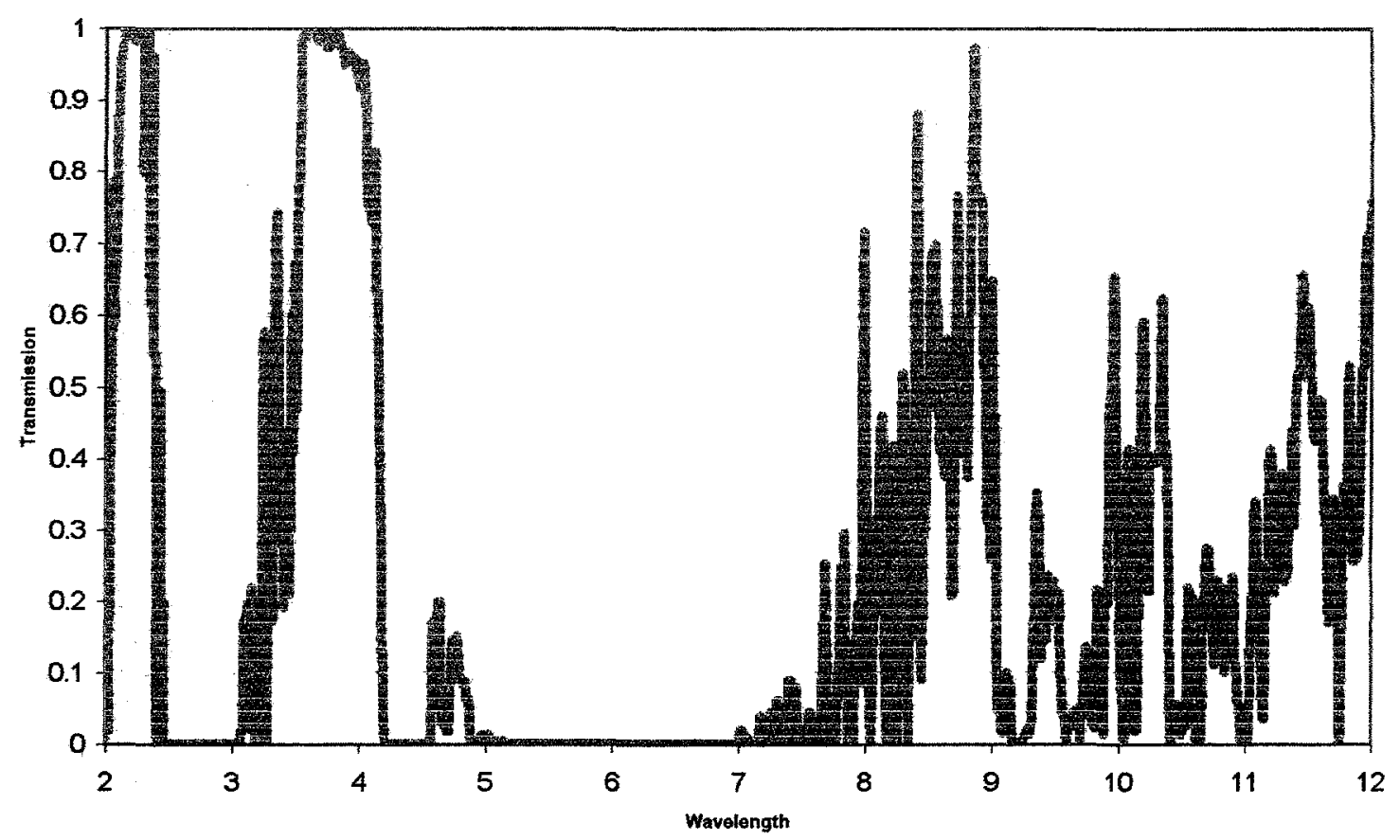

Figure 1: Absorption vs. Wavelength for a typical boiler with a 10-m optical path length.

\section{Experimental Work: 3.9 Micron Window}

The project team had previously experimented with three imaging devices: a ferroelectric array camera (using a Raytheon series 200 camera core), a PtSi camera (FLIR Model FSI), and a Si microbolometer array camera (Merlin-Boeing Gen II Camera assembled by Indigo systems).

In the current period, the project team investigated the use of an Indigo $320 \times 240 \mathrm{InSb}$ Array Camera. As before, this device was incorporated into a simple prototype imaging system, the components of which are show in Figure 2.

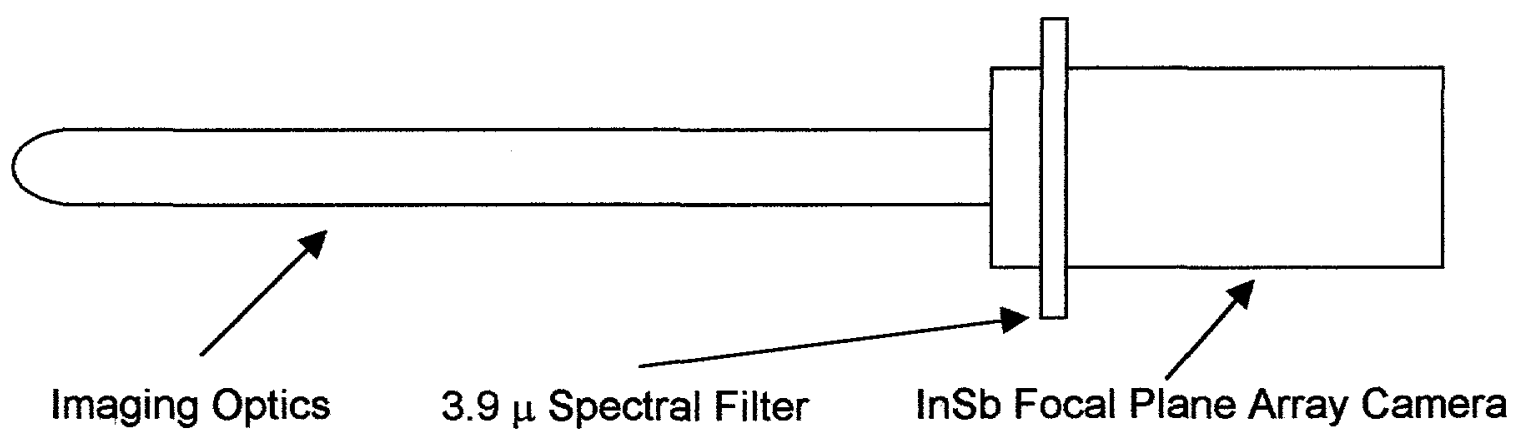

Figure 2: Components of Imaging System 
We made use of imaging optics consisting of a train of $\mathrm{ZnSe}$ lenses with an $8^{\circ}$ field of view protected by a double-layered air-cooled steel lens tube. This preceded a 3.9 micronfilter followed by the InSb array.

Our first images were acquired by positioning the lens tube in a port in the front wall of Weyerhaeuser's Longview recovery boiler, opposite the pendant tubes. Two representative images are shown in Figure 3. The deposits on each pendant tube are clearly visible.
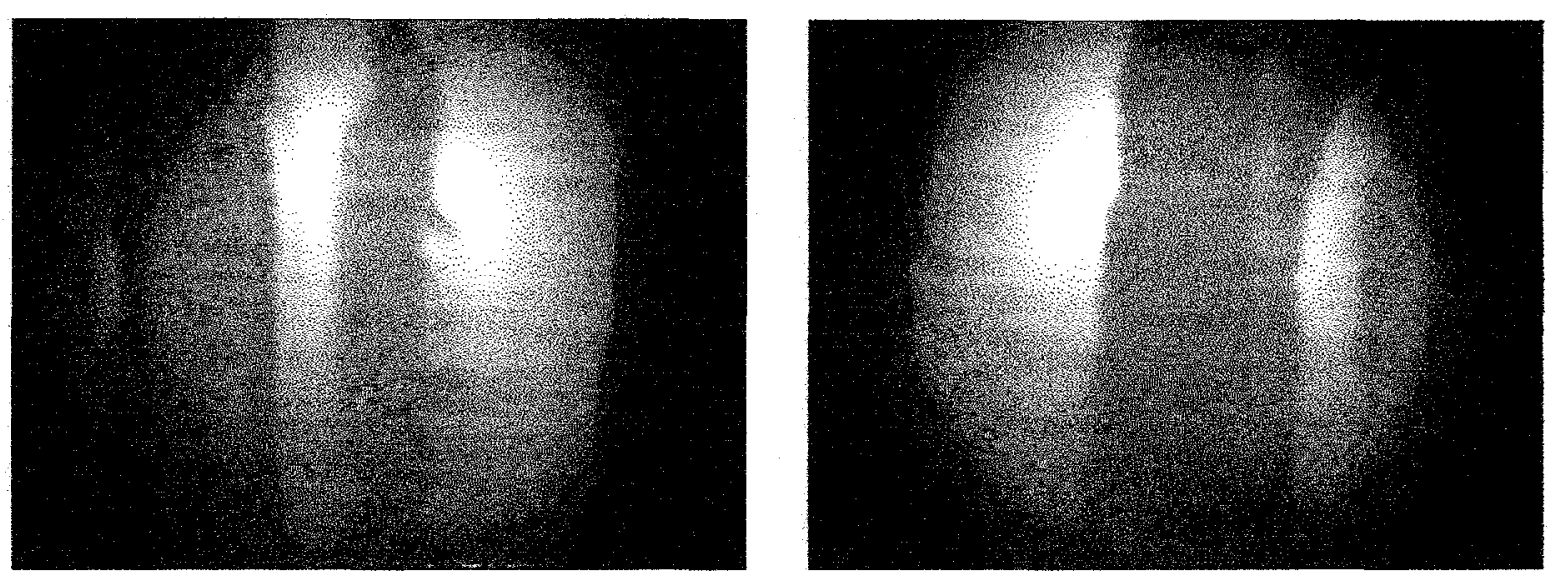

Figure 3: Pendant Tube Deposits

To verify that we could readily see across the full width of the boiler, we moved the imaging system to the side of the boiler, and looked down the third sootblower lane (the boiler interior here looks completely dark to the naked eye). Two of the images acquired are shown in Figure 4. In the left-hand image we clearly see a dark vertical rectangle corresponding to an observation door on the opposite side of the boiler. In the right-hand image, a one-inch diameter pipe has been inserted into the port; this is clearly evident in the image, and gives an indication of the spatial resolution that is readily achievable, even under full load conditions.
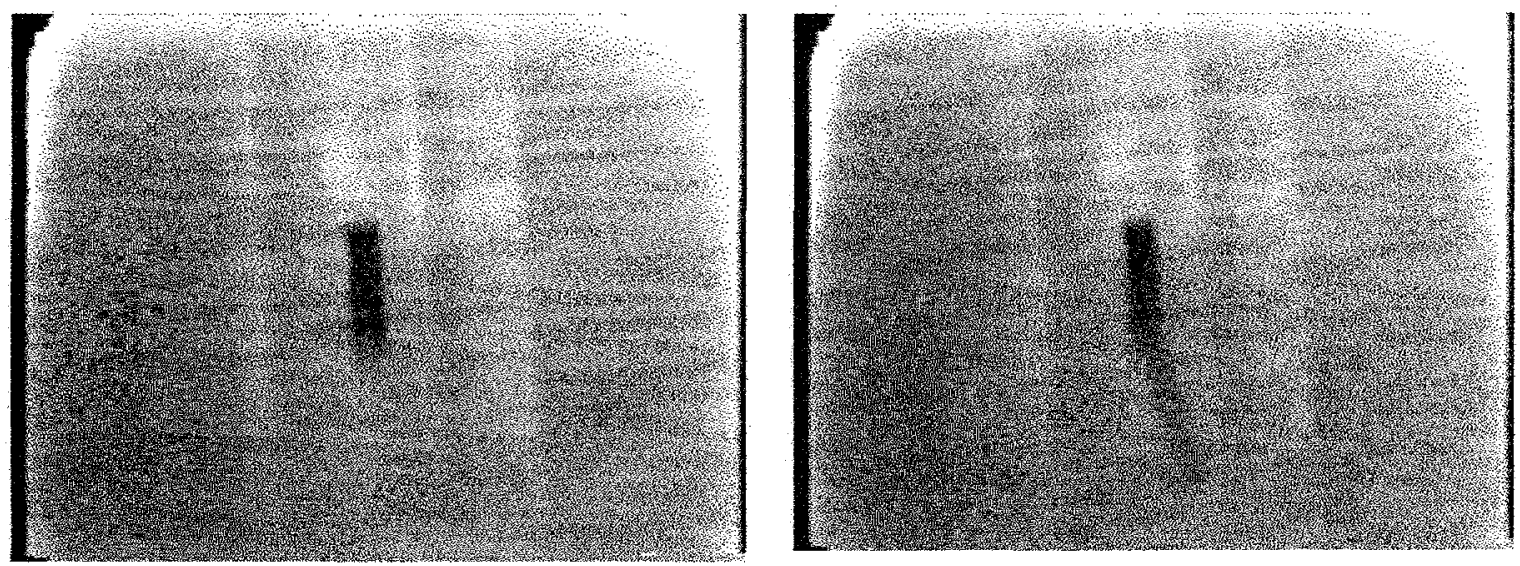

Figure 4: Port Across Full-Width of Recovery Boiler 


\section{Implications}

These data suggest that the 3.9-micron window is good for observing recovery boiler interiors. Unfortunately InSb imaging systems are not practical devices to deploy in recovery boilers owing to their cost, and the limited lifetimes of the cooling systems leading to unacceptable maintenance requirements. These considerations make it much more attractive to make use of a ferroelectric array camera. However, the only currently commercially available cameras have a window in front of the imaging array, which restricts the sensitivity to the 8 to 12 micron range. Thus we will be exploring the 8-9 microp range in future work.

We now have images of sufficient quality to initiate Task 5 of our project: Data Processing Definition and Implementation. In order to acquire images suitable for data processing, we have modified out imaging optics with a larger field of view objective. We are now preparing to field test this arrangement.

\section{Sootblower Operation}

Next we were able to capture a complete sequence of a sootblower in operation. We were able to observe this operation in great detail, with the effect of the cleaning process clearly apparent. Several images from this sequence are shown in Figure 5 on the following page, but much of the impact of the video is lost in this presentation. The quality of the video suggests that this imaging system would be a valuable tool for diagnosing sootblower problems. 

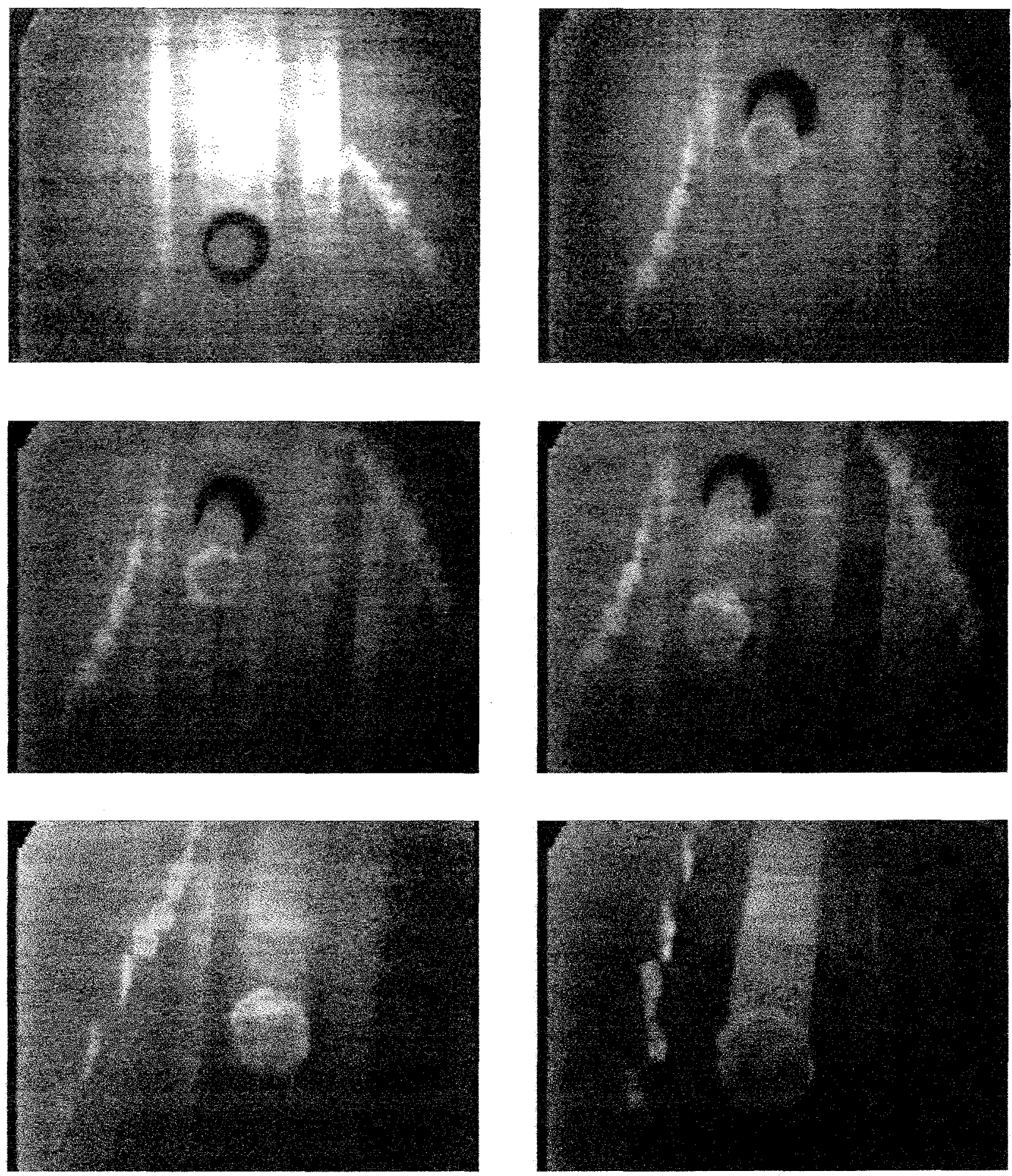

Figure 5: Sootblower Operation Sequence 


\section{Percentage Completion of Each Task}

This is shown in the following table:

Table 2.

\begin{tabular}{|l|c|}
\hline \multicolumn{1}{|c|}{ Task } & $\begin{array}{c}\text { Percent } \\
\text { Complete }\end{array}$ \\
\hline 1. Electromagnetic Properties Survey & $90 \%$ \\
\hline 2. Detection Technology Survey & $100 \%$ \\
\hline 3. Device Selection and Packaging & $70 \%$ \\
\hline 4. Boiler Data Acquisition & $35 \%$ \\
\hline 5. Data Processing Definition/Implementation & $5 \%$ \\
\hline 6. Prototype System Assembly & $0 \%$ \\
\hline 7. Pluggage Control Demonstration & $0 \%$ \\
\hline
\end{tabular}

\section{Variances to Cost or Project Schedule}

Prorating the CSI portion of the DOE contract, the projected spending rate of DOE funds for the first 12 months should be about $\$ 10,000$ per month. Through September, about 8 months of the project has been completed.

Table 3

\begin{tabular}{|c|c|c|}
\hline Projected Budget ( mo) & Actual Expenditure ( mo) & Variance ( mo) \\
\hline$\$ 80,000$ & $\$ 78,344$ & $4 .(\$ 1,656)$ \\
\hline
\end{tabular}


The project schedule originally proposed was:

Table 4

\begin{tabular}{|l|l|l|l|l|l|l|l|l|l|l|l|l|}
\hline \multicolumn{1}{|c|}{ Task } & $\mathbf{Q}$ & $\mathbf{Q}$ & $\mathbf{Q}$ & $\mathbf{Q}$ & $\mathbf{Q}$ & $\mathbf{Q}$ & $\mathbf{Q}$ & $\mathbf{Q}$ & $\mathbf{Q}$ & $\mathbf{Q}$ & $\mathbf{Q}$ & $\mathbf{Q}$ \\
& $\mathbf{1}$ & $\mathbf{2}$ & $\mathbf{3}$ & $\mathbf{4}$ & $\mathbf{5}$ & $\mathbf{6}$ & $\mathbf{7}$ & $\mathbf{8}$ & $\mathbf{9}$ & $\mathbf{1 0}$ & $\mathbf{1 1}$ & $\mathbf{1 2}$ \\
\hline 1.Enviromental Transmission Properties & & & & & & & & & & & & \\
\hline 2. Detection Technology Survey & & & & & & & & & & & & \\
\hline 3. Device Selection and Packaging & & & & & & & & & & & & \\
\hline 4. Boiler Data Acquisition & & & & & & & & & & & \\
\hline 5. Data Processing Definition/Implementation & & & & & & & & & & & \\
\hline 6. Prototype System Assembly & & & & & & & & & & & \\
\hline 7. Pluggage Control Demonstration & & & & & & & & & & & \\
\hline
\end{tabular}

We are currently in the middle of Q3. Comparing this table with Table 1 we see that we are on track with Tasks 1,2, and Task 3, and somewhat ahead with Task 4. We anticipate starting Task 5 in Q4, slightly ahead of schedule.

\section{Estimate of Costs for Next Six Months}

We anticipate that the base rate of spending by CSI for the next 6 months will continue to run at about $\$ 10,000$ per month. In addition, we will need to make some significant equipment purchases as we assemble our prototype system; we currently project that this will consume about $\$ 30,000$. For the last four months of this period, we will be also be initiating image-processing work by our consultant, Dr. Dan Davis. This activity is expected to consume about $\$ 5,000$ per month.

The total spending of DOE funds for the next six months is likely to be around $\$ 110,000$, which together with spending to-date will bring the total of DOE funs expended to about $\$ 190,000$.

\section{Significant Accomplishments for Next Six Months}

During the next 6 months, our primary goal will be to obtain clear images of the boiler interior under a variety of circumstances, allow visual determination of the boiler tube deposits. We expect to:

1. Complete and test our larger field of view lens tube.

2. Investigate imaging in the 8-9 micron range using the ferroelectric array camera.

3. Finalize selection of the primary imaging device that we will be using for the rest of the project. 
4. Modify and package this device is a way will make it readily and conveniently usable for long periods at boiler side.

5. Complete at least two additional tests, capturing a range of good quality deposition images.

6. Start development of image processing methods to quantify the information in the images.

gk:oct'99 report doc 